\section{TÀI LIẸU THAM KHẢO}

1. Yamaoka $Y$. Mechanisms of disease: Helicobacter pylori virulence factors. Nat Rev Gastroenterol Hepatol. 2010;7(11): 629-641.

2. Yamaoka Y, Souchek J, Odenbreit S, et al. Discrimination between cases of duodenal ulcer and gastritis on the basis of putative virulence factors of Helicobacter pylori. Journal of clinical Microbiology 2002;40(6): 2244-2246

3. Khatoon J, Prasad KN, Prakash RR, et al. Association of heterogenicity of Helicobacter pylori cag pathogenicity island with peptic ulcer diseases and gastric cancer. Br. J. Biomed Sci 2017;74(3): 121-126

4. Liu J, He $C$, Chen $M$, et al. Association of presence/absence and on/off patterns of Helicobacter pylori oipA gene with peptic ulcer disease and gastric cancer risks: A meta-analysis. BMC Infectious Disease 20-13;13: 555-564

5. Braga LLBC, Batista MHR, de Azevedo OGR, et al. OipA "on" status of Helicobacter pylori is associated with gastric cancer in North-Eastern Brazil. BMC Cancer 2019;19(1):48

6. Lu $H$, Hsu $P$, Graham DY, Yamaoka $Y$. Duodenal ulcer promoting gene of Helicobacter pylori. Gastroenterology. 2005;128(4): 833-848.

7. Zhang Z, Zheng Q, Lu $\mathbf{H}$, et al. The Helicobacter pylori duodenal ulcer promoting gene, dupA, in China. BMC Gastroenterol. 2008; 8: 49-54.

8. Alam J, Sarkar A, Karmadar BC, et al. Novel virulence factor dupA of Helicobacter pylori as an important risk determinant for disease manifestion: An overview. World Journal of Gastroenterology 2020;26(32): 4739-4752

\title{
HÀNH VI CỦA LÁI XE KHÁCH ĐƯờNG DÀI VÀ TAI NẠN GIAO THÔNG
}

\section{TÓM TẮT}

Nghiên cứu được tiến hành nhằm tìm hiểu môt sỗ yếu tố hành vi của lái xe khách đường dài và mối liên quan với tai nan giao thông. 200 nam lái xe khách đường dài tuyển cố đinh liên tỉnh với tuổi đời trung bình là 40,9 45,6 tuổi và tuổi nghề trung bình là $12,4 \pm 5,6$ năm đã tham gia nghiên cứu. Các lái xe được phân tích đặc điểm công việc; điều tra, đánh giá hành vi theo thang DBQ (Driver Behaviour Questionnair có chỉnh sưaa) và hồi cứu số liệu tai nạn giao thông trong 3 năm liên tưc tai doanh nghiếp. Kết quả nghiên cứu cho thấy: Công việc của lái xe khách đường dài gây căng thẳng thần kinh tâm lý, thời gian lao động kéo dài, chế độ thay ca không ổn định, thường xuyên phải lái đêm, làm viêc trong tư thế bất lợi (phải ngồi lâu trong thời gian dài)... Các hành vi của lái xe: $52,5 \%$ mêt mỏi; $30,0 \%$ kiểm soát nguy co không tốt; $42,5 \%$ kém thư giãn; 44,5\% kém kiên nhẫn; 35,0\% lo lắng khi lái xe. Nguy cơ tai nan giao thông ở nhóm lái xe khách đường dài có biểu hiện trang thái mệt mỏi cao gấp 2,1 lần so với nhóm không có biểu hiện trạng thái mêt mỏi $(95 \% \mathrm{CI}=1,0-4,4)$; có điểm kiểm soát nguy cơ không tốt cao gấp 3,4 lần so với nhóm có điểm kiểm soát nguy cơ tốt $(95 \% \mathrm{CI}=1,6$ 7,2); điểm kiên nhẫn khi lái xe không tốt cao gấp 4,7 lần so với nhóm có điểm kiên nhẩn khi lái xe tốt $(95 \% \mathrm{CI}=2,0-11,3)$ với $\mathrm{p}<0.05 ; \mathrm{p}<0,01$ and $\mathrm{p}<0,001$. Các tác giả khuyến nghị cần áp dụng giải pháp kiểm soát hành vi lái xe góp phần giảm thiểu tai nạn giao thông.

Tư khoá: Hành vi, lái xe khách đường dài, tai nạn giao thông,

*Viên Sức khỏe nghề nghiêp và môi trường

Chịu trách nhiệm chính: Nguyễn Thu Hà

Email: thuhayhld@gmail.com

Ngày nhận bài: 3.6.2021

Ngày phản biên khoa hoc: 26.7.2021

Ngày duyệt bài: 3.8.2021
Nguyễn Thu Hà*, Nguyễn Đức Sơn*

\section{SUMMARY}

\section{BEHAVIOUR OF LONG DISTANCE DRIVER} AND TRAFFIC CCIDENTS

This study was carried out to to investigate some behaviour factors of long distance drivers and relationship with traffic accidents. 200 male drivers with $40.9 \pm 5.6$ years of age and $12.4 \pm 5.6$ participated in this study. The drivers are analyzed for job characteristics; investigating and evaluating sleep disorder according to Driver Behaviour Questionnair (DBQ) and retrospective traffic accident data for 3 years at the enterprise. The result showed that: The job characteristics of long distance drivers are high intensity of work; a working long time, unstable time; a night duty; a high responsibility, long sitting hours, ect... The driver's behavior: $52.5 \%$ were tired; $30.0 \%$ non-good risk control score; $42.5 \%$ less relaxed; $44.5 \%$ are impatient; $35.0 \%$ worry about driving. In the long-distance driver, the risk of traffic accidents of fatigue group was higher 2.1 times $(95 \% \mathrm{CI}=1.0$ 4.4); bad risk control score group was higher 3.4 times (95\% CI $=1.6-7.2)$; bad driving patience score group was higher 4.7 times $(95 \% \mathrm{CI}=2.0-11.3)$ than that among other group with $\mathrm{p}<0.05 ; 0.01$ and 0.001 . The author recommended that it is necessary to control behaviour of drivers to help reduce traffic accidents.

Keywords: Behaviour, long distance drivers, traffic accident

\section{I. ĐĂT VẤN ĐỀ}

Hành vi của lái xe (sử dụng điên thoai di đông, thiếu kiên nhẫn, kiểm soát nguy cơ không tốt, mệt mỏi...) và an toàn giao thông có mối liên quan với nhau. Khi lái xe bị phân tâm bởi điện thoại di động có thể làm thay đổi tốc độ lái xe dẫn đến mâu thuẫn với người tham gia giao thông (kiểm soát nguy cơ không tốt) và do đó tăng nguy cơ tai nạn. 
Để đánh giá hành vi của lái xe, $\mathrm{DBQ}$ (Driver Behaviour Questionnaire) là một trong những bộ công cụ có độ tin cậy cao và được sử dụng ở nhiều nước. Alavi SS (2016) [1] đánh giá tại Manchester trên 800 lái xe ở 6 yếu tố cho thấy độ tin cậy của các yếu tố dao động của bộ công cụ này từ 0,65 đến 0,75 . Koppel S (2018) [4] sử dụng $\mathrm{DBQ}$ nhằm kiểm tra việc tự đánh giá hành vi lái xe có thay đổi theo thời gian ở 227 lái xe trong 3 năm liền. Kết quả cho thấy bảng $\mathrm{DBQ}$ (21 mục với 3 yếu tố lỗi, sai sót và vi phạm) là ổn định. Những kết quả này cho thây $\mathrm{DBQ}$ là một công cụ đáng tin cậy để đo lường các hành vi ở lái xe. Mục tiêu nghiên cứu

- Tìm hiểu một số yếu tố hành vi của lái xe khách đường dài

- Tìm hiểu mối liên quan của một số hành vi của lái xe khách đường dài và tai nạn giao thông

\section{II. ĐỐI TƯợNG VÀ PHƯƠNG PHÁP NGHIÊN CứU}

1. Đối tượng nghiên cứu. 200 nam lái xe khách đường dài tuyến cố định liên tỉnh thuộc 5 doanh nghiệp vận tải có hành trình chạy xe qua tuyến quốc lộ $1 \mathrm{~A}$.

\section{Phương pháp nghiên cứu}

2.1. Thiết kế nghiên cứu: Nghiên cứu mô tả cắt ngang

2.2. Chỉ tiêu và phương pháp

2.2.1. Một số hành vi của lái xe khách đường dài. Sử dụng thang DBQ - Driver Behaviour Questionnair có chỉnh sửa, bao gồm:

Yếu tố 1: Trạng thái mệt mỏi (11 thành phần)

Yếu tố 2: Kiểm soát nguy cơ (14 thành phần)

Yếu tố 3: Thư giãn khi lái xe (9 thành phần)

Yếu tố 4: Kiên nhẫn trong lái xe (12 thành phần)

Yếu tố 5: Lo lắng khi lai xe (13 thành phần)

2.2.2. Tìm hiểu mối liên quan của một số hành vi của lái xe khách đường dài và tai nạn giao thông

- Hồi cứu số liệu về tai nạn giao thông tại doanh nghiệp

- Phân tích mối liên quan một số hành vi của lái xe khách đường dài và tai nạn giao thông

2.3 Xử lý số liệu theo phương pháp thống kê y học và chương trình phần mềm SPSS 20.0

\section{KẾT QUẢ NGHIÊN CỨU}

3.1 Đặc điểm yêu câu công việc của lái xe khách đường dài tuyến cố định liên tỉnh
- Thường xuyên làm việc trong môi trường căng thẳng thần kinh tâm lý (công việc đòi hỏi phải có trí nhớ tốt; cần những quyết định nhanh, kịp thời, chính xác, phản ứng nhanh...), dễ gây mệt mỏi, buồn ngủ; thiếu kiên nhẫn, bình tĩnh khi lái xe; có nhiều tình huống bất ngờ, yễu tố bất trắc trên đường.

- Thời gian lao động kéo dài, chế độ thay ca không ổn định, thường xuyên phải lái đêm; (các tuyến $<300 \mathrm{~km}$ các lái xe phải lái quay vòng trong ngày; đặc biệt với các tuyến đường dài $>300$ km như tuyến Hà Nội - Sài Gòn)

- Làm việc trong tư thế bất lợi (phải ngồi lâu trong thời gian dài), tiếp xúc với rung toàn thân

3.2 Một số yếu tố hành vi của lái xe khách đường dài

Bảng 1. Mốt số yêu tố hành vi của lái xe

Các hành vi của lái xe Số đối

\begin{tabular}{|c|c|c|}
\hline$(n=200)$ & tượng (n) & $(\%)$ \\
\hline $\begin{array}{c}\text { Yếu tố 1: Trạng thái mệt } \\
\text { mỏi }\end{array}$ & 105 & 52,5 \\
\hline $\begin{array}{c}\text { Yếu tố 2: Kiếm soát nguy cơ } \\
\text { không tốt }\end{array}$ & 60 & 30,0 \\
\hline $\begin{array}{l}\text { Yếu tố 3: Kém thư giãn khi } \\
\text { lái xe }\end{array}$ & 85 & 42,5 \\
\hline $\begin{array}{l}\text { Yếu tố 4: Kém kiên nhân khi } \\
\text { lái xe }\end{array}$ & 89 & 44,5 \\
\hline Yếu tố 5: Lo lắng khi lái xe & 70 & 35,0 \\
\hline
\end{tabular}

Các hành vi của lái xe khi đánh giá: $52,5 \%$ có biểu hiện mệt mỏi; $30,0 \%$ kiểm soát nguy cơ không tốt; $42,5 \%$ kém thư giãn khi lái xe; $44,5 \%$ kém kiên nhẫn khi lái xe; 35,0\% có biểu hiện lo lắng khi lái xe.

3.3. Tìm hiểu mối liên quan một số yếu tố hành vi của lái xe khách đường dài và tai nạn giao thông

Bảng 2. Hồi cứu về tai nạn giao thông ở các lái xe đường dài

\begin{tabular}{|c|c|c|}
\hline $\begin{array}{c}\text { Hồi cứu về tai nạn giao } \\
\text { thông (n=200) }\end{array}$ & $\mathbf{n}$ & \% \\
\hline $\begin{array}{c}\text { Có số liệu hồi cứu chi tiết về tai } \\
\text { nạn giao thông }\end{array}$ & 132 & 66,0 \\
\hline $\begin{array}{c}\text { Không cô số liệu hồi cứu chi tiết } \\
\text { về tai nạn giao thông }\end{array}$ & 68 & 34,0 \\
\hline
\end{tabular}

Trong số 200 lái xe tham gia nghiên cứu, 132 lái xe $(66,0 \%)$ được hồi cứu chi tiết về tai nạn giao thông trong 3 năm qua thông qua quản lý lý lịch cá nhân của lái xe.

Bảng 3. Hồi cứu về tai nạn giao thông trong 3 năm

\begin{tabular}{|c|c|c|c|c|c|c|}
\hline \multirow{2}{*}{ Ghi nhận về tai nạn giao thông (n=132) } & \multicolumn{2}{|c|}{$\mathbf{2 0 1 6}$} & \multicolumn{2}{|c|}{$\mathbf{2 0 1 5}$} & \multicolumn{2}{c|}{$\mathbf{2 0 1 4}$} \\
\cline { 2 - 7 } & $\mathbf{n}$ & $\mathbf{\%}$ & $\mathbf{n}$ & $\mathbf{9}$ & $\mathbf{n}$ & $\mathbf{\%}$ \\
\hline Số lái xe có ghi nhận tai nạn giao thông & 20 & 15,2 & 21 & 15,9 & 13 & 9,8 \\
\hline Tống số vụ/ lượt ghi nhận tai nạn giao thông & \multicolumn{2}{|c|}{25} & \multicolumn{2}{|c|}{26} & \multicolumn{2}{|c|}{16} \\
\hline
\end{tabular}




\begin{tabular}{|c|c|c|c|}
\hline Số vụ/ lượt lái xe ghi nhận tai nạn giao thông & $\begin{array}{c}1,25 \pm 0,71 \\
(1-4)\end{array}$ & $\begin{array}{c}1,24 \pm 0,44 \\
(1-2)\end{array}$ & $\begin{array}{c}1,23 \pm 0,44 \\
\text { trung bình }\end{array}$ \\
\hline
\end{tabular}

$(15,9 \%)$ và năm 2014 là $12 / 132(9,8 \%)$. Tổng số vu/ lượt ghi nhận tai nạn giao thông có xu hướng gia tăng trong năm 2016 và 2015 hơn so với năm 2014.

Bảng 4. Môi liên quan giữa điểm trạng thái mệt mỏi và tai nạn giao thông

\begin{tabular}{|c|c|c|c|c|c|c|c|}
\hline \multirow{2}{*}{$\begin{array}{l}\text { Trạng thái } \\
\text { mệt mói (YT1) }\end{array}$} & \multicolumn{2}{|c|}{ Đã từng TNGT } & \multicolumn{2}{|c|}{ Chưa bị TNGT } & \multirow[b]{2}{*}{$\mathbf{p}$} & \multirow{2}{*}{ OR } & \multirow{2}{*}{$95 \% \mathrm{CI}$} \\
\hline & $\mathbf{n}$ & $\%$ & $\mathbf{n}$ & $\%$ & & & \\
\hline Có & 33 & 66,0 & 39 & 47,6 & $<005$ & 21 & $10-44$ \\
\hline Không & 17 & 34,0 & 43 & 52,4 & $<0,05$ & 2,1 & $1,0-4,4$ \\
\hline Tống $(n=132)$ & 50 & 100 & 82 & 100 & & & \\
\hline
\end{tabular}

Nguy cơ tai nạn giao thông ở nhóm lái xe khách đường dài có biếu hiên trạng thái mêt mỏi cao gấp 2,1 lần so với nhóm không có biểu hiện trạng thái mệt mỏi $(66,0 \%$ so với $47,6 \% ; p<0,05$; $95 \% \mathrm{CI}=1,0-4,4)$.

Bảng 5. Mối liên quan giứa điểm kiểm soát nguy cơ và tai nạn giao thông

\begin{tabular}{|c|c|c|c|c|c|c|c|}
\hline \multirow{2}{*}{$\begin{array}{l}\text { Kiếm soát nguy } \\
\text { cơ (YT2) }\end{array}$} & \multicolumn{2}{|c|}{ Đã từng TNGT } & \multicolumn{2}{|c|}{ Chưa bị TNGT } & \multirow[b]{2}{*}{$\mathbf{p}$} & \multirow{2}{*}{ OR } & \multirow{2}{*}{$95 \% \mathrm{CI}$} \\
\hline & $\mathbf{n}$ & $\%$ & $n$ & $\%$ & & & \\
\hline Không tốt & 28 & 56,0 & 22 & 26,8 & $<0.01$ & 34 & $1,6-7,2$ \\
\hline Tốt & 22 & 44,0 & 60 & 73,2 & $<0,01$ & & $1,0-1,2$ \\
\hline Tống (n=132) & 50 & 100 & 82 & 100 & & & \\
\hline
\end{tabular}

Nguy cơ tai nạn giao thông ở nhóm lái xe khách đường dài có điểm kiếm soát nguy cơ không tốt cao gấp 3,4 lần so với nhóm có điểm kiểm soát nguy cơ tốt $(56,0 \%$ so với $26,8 \% ; p<0,05$; 95\% $\mathrm{CI}=1,6-7,2)$.

Bảng 6. Môi liên quan giữa kiên nhẫn khi lái xe và tai nạn giao thông

\begin{tabular}{|c|c|c|c|c|c|c|c|}
\hline \multirow{2}{*}{$\begin{array}{l}\text { Kiên nhần khi } \\
\text { lái xe (YT4) }\end{array}$} & \multicolumn{2}{|c|}{ Đã từng TNGT } & \multicolumn{2}{|c|}{ Chưa bị TNGT } & \multirow[b]{2}{*}{$\mathbf{p}$} & \multirow{2}{*}{ OR } & \multirow{2}{*}{$95 \% \mathrm{CI}$} \\
\hline & $\mathbf{n}$ & $\%$ & $\mathbf{n}$ & $\%$ & & & \\
\hline Không tốt & 42 & 84,0 & 43 & 52,4 & & 47 & \\
\hline Tốt & 8 & 16,0 & 39 & 47,6 & $<0,001$ & 4,7 & $2,0-11,3$ \\
\hline Tống $(n=132)$ & 50 & 100 & 82 & 100 & & & \\
\hline
\end{tabular}

Nguy cơ tai nạn giao thông ở nhóm lái xe khách đường dài có điếm kiên nhần khi lái xe không tốt cao gấp 4,7 lần so với nhóm có điểm kiên nhẫn khi lái xe tốt $(84,0 \%$ so với $52,4 \%$; $p<0,05$; $95 \% \mathrm{CI}=2,0-11,3)$.

\section{BÀN LUẬN}

Lái xe là một trong những nghề đặc thù. Các yếu tố hành vi của lái xe và an toàn giao thông được nhiều tác giả quan tâm, nghiên cứu.

Các hành vi không an toàn (không kiểm soát được nguy cơ, kém kiên nhẫn khi lái xe vv...) là những nguyên nhân chính gây ra tai nạn chủ yếu (ảnh hưởng của đặc điểm cá nhân, môi trường xã hội, chu kỳ sinh học cá nhân...) Nghiên cứu của Kamari Ghanavati $F$ (2018) [3] được thực hiện trên 224 lái xe buýt ở Shiraz, Iran, kết quả cho thây. Tỷ lệ có hành vi không an toàn là 54,08 trong số các đối tượng nghiên cứu.

Bener $\mathrm{A}$ (2013) [2] điều tra 1824 bằng bảng câu hỏi $\mathrm{DBQ}$. Kết quả cho thấy các lái xe đã từng xảy ra các vụ tai nạn ở người Qatari là $52 \%$, người Jordani là 48,3\%. Lỗi thông thường nhất là kém quan sát khi rẽ phải/trái vào đường chính, va cham khi quay đầu xe.

Pourabdian S (2013) [5] sử dụng bảng câu hỏi về hành vi lái xe trên 168 lái xe đã từng xảy ra tai nạn. Các yếu tố vi phạm (bình thường và hung hãn) là các hành vi phổ biến nhất ở các lái xe. Điểm trầm cảm có liên quan đáng kể với hành vi lái xe, đặc biệt là lỗi sai sót có liên quan nghịch với tuổi $(p<0,01)$.

Qu W (2016) [6] tìm hiểu mối tương quan giữa các hành vi nguy hiểm của lái xe với trang thái mệt mỏi, stress ở 246 lái xe cho thấy trạng thái mểt mỏi, stress ở lái xe có tương quan trung bình hoắc yếu với hành vi nguy hiểm của lái xe. Kiểm soát các yếu tố nguy cơ và sự mệt mỏi có tượng quan yếu với tai nạn. Và lái xe đã vi phạm tốc độ, vi phạm giao thông (trong ba năm gần đây) có sự hung hăng và tìm kiếm cảm giác mạnh hơn khi lái xe so với những người không vi phạm.

\section{KẾT LUÂN}

- Các hành vi của lái xe: $52,5 \%$ mệt mỏi; 30,0\% kiểm soát nguy cơ không tốt; 42,5\% kém thư giãn; 44,5\% kém kiên nhẫn; 35,0\% lo lắng khi lái xe.

- Nguy cơ tai nạn giao thông ở nhóm lái xe khách đường dài có biểu hiện trang thái mêt mỏi cao gấp 2,1 lần so với nhóm không có biểu hiện 
trang thái mêt mỏi $(95 \% \mathrm{CI}=1,0-4,4)$; có điểm kiểm soát nguy cơ không tốt cao gấp 3,4 lần so với nhóm có điểm kiểm soát nguy cơ tốt $(95 \% C I=1,6-7,2)$; điểm kiên nhẫn khi lái xe không tốt cao gấp 4,7 lần so với nhóm có điểm kiên nhẫn khi lái xe tốt $(95 \% \mathrm{CI}=2,0-11,3)$.

\section{KHUYẾN NGH!}

Các tác giả khuyến nghị cần áp dụng giải pháp kiểm soát hành vi của lái xe góp phần giảm thiểu tai nạn giao thông.

\section{TÀI LIÊU THAM KHẢO}

1. Alavi SS, Mohammadi M, Soori H et al (2016). Iranian Version of Manchester Driving Behavior Questionnaire (MDBQ): Psychometric Properties. Iran J Psychiatry. 2016 Jan; 11(1):37-42

2. Bener A, Verjee M, Dafeeah EE, Yousafzai MT et al (2013). A cross "ethnical" comparison of the Driver Behaviour Questionnaire (DBQ) in an economically fast developing country. Glob J Health Sci. 2013 May 12;5(4):165-75

3. Kamari Ghanavati $F$, Jahangiri $\mathbf{M}$, Khalifeh $\mathbf{M}$ et al (2018). "The effect of biological rhythms and personality traits on the incidence of unsafe behaviors among bus drivers in Shiraz, Iran". J Inj Violence Res. 2018 Jan;10(1):3-10.

4. Koppel S, Stephens AN, Charlton JL et al (2018). "The Driver Behaviour Questionnaire for older drivers: Do errors, violations and lapses change over time?". Accid Anal Prev. 2018 Feb 5;113:171-178.

5. Pourabdian S, Azmoon H (2013). The Relationship between Trait Anxiety and Driving Behavior with Regard to Self-reported Iranian Accident Involving Drivers. Int J Prev Med. 2013 Oct; 4(10):1115-21.

6. Qu W, Zhang Q, Zhao W et al (2016), Validation of the Driver Stress Inventory in China: Relationship with dangerous driving behaviors, Accid Anal Prev. 2016 Feb;87:50-8. Epub 2015 Nov 29.

\section{KẾT QUẢ PHẪU THUÂTT NộI SOI CHİNH HÌNH VÁCH NGĂN MŨI CÓ SỬ DỤNG MEROCEL CÓ ỐNG THÔNG}

\section{TÓM TẮT}

Muc tiêu nghiên cứu: Kết quả phẫu thuật nội soi chỉnh hình vách ngăn mũi có sử dụng Merocel có ống thông. Thiết kế nghiên cứu: tiến cứu. Nơi thực hiện: Bệnh viện đại học y Hà Nội từ 9/2020 đển 8/2021. Đối tương: 23 bênh nhân được chẩn đoán là dị hình vách ngẳn, được phẫu thuật nội soi chỉnh hình vách ngăn mữi có sử dụng merocel có ống thong. Kết quả: Sau phẫu thuật 24h, 23/23 bệnh nhân thở được qua merocel có ống thông, đau hổc mổ gắp ở 19/23 bệnh nhân với điểm VAS trung bình là $2.78 \pm 1.88$. Không có bênh nhân nào mất ngửi, đau tai, ù tai. Không có bệnh nhân nào có biến chứng tụ máu vách ngăn, nhiếm trùng, có 1 bệnh nhân chảy máu ngay sau phẫu thuật chiếm tỉ lệ $4.3 \%$. Kết luận: Nội soi chỉnh hình vách ngăn có sử dụng merocel có ống thông đạt được kết quả tốt, bệnh nhân có thể thở bằng mũi qua ống thông, do vậy làm giảm các triệu chứng khó chịu (đau đâu, ho, ù tai...) giúp nâng cao chất lượng điều trì cho bệnh nhân.

Tư khóa: phẫu thuật chỉnh hình vách ngăn mũi, merocel mũi có ống thông,

\section{SUMMARY}

\section{RESULTS OF ENDOSCOPY SEPTOPLASTY}

\author{
${ }^{1}$ Bệnh viện trường Đại học Kỹ thuật y tế Hải Dương \\ 2Bềnh viện Đại học Y Hà Nôi \\ Chịu trách nhiệm chính: Trần Văn Minh \\ Email: hoangtuhmu@gmail.com \\ Ngày nhận bài: 4.6.2021 \\ Ngày phản biên khoa hoc: 27.7.2021 \\ Ngày duyệt bài: 5.8 .2021
}

\section{Trần Văn Minh¹, Cao Minh Thành² \\ USE MEROCEL WITH AIRWWAY}

Objective: Results of endoscopic septoplasty using merocel with airway. Study design: Prospective study. Setting: In $\mathrm{Ha}$ Noi medical university Hospital. Patients: 23 patients having nasal septum deviation were endoscopic septoplasty using merocel with airway. Results: 24 hours after surgery, $23 / 23$ patients breathe well through merocel with airway. The mean scores of nasal pain was $2.78 \pm$ 1.88. No patient loss of smell, ear pain and tinnitus. In the retainer group, the incidence of grade 1 bleeding was $4.3 \%$, no patient had an infection, heamatoma and septal perforation. Conclusion : Results of endoscopic septoplasty using merocel with airway is good without complication

Key words; septoplasty, merocel with airway.

\section{I. ĐẶT VẤN ĐỀ}

Di hình vách ngăn mũi là môt bênh lý thường gặp ở người Việt Nam. Dị hình vách ngăn mũi có thể gặp là: lệch, vẹo, mào, gai hoặc dày chân vách ngăn mà nguyên nhân do sự phát triển bất thường của vách ngăn mũi hoặc các khối xương có liên quan, do chấn thương ${ }^{i}$. Hậu quả của di hình vách ngăn thường gây hẹp hốc mũi bên di hình, cản trở thông khí, giảm thông khí. Biểu hiện lâm sàng khác nhau ở mỗi người, mỗi loại dị hình và mức độ dị hình, có thể là yếu tố thuận lợi trong bệnh viêm mũi xoang, hoặc gây viêm mũi xoang kéo dài. Chỉnh hình vách ngăn có rất nhiều kỹ thuật và phương pháp, phương pháp phổ biến hiện nay là phẩu thuật nội soi chỉnh 